
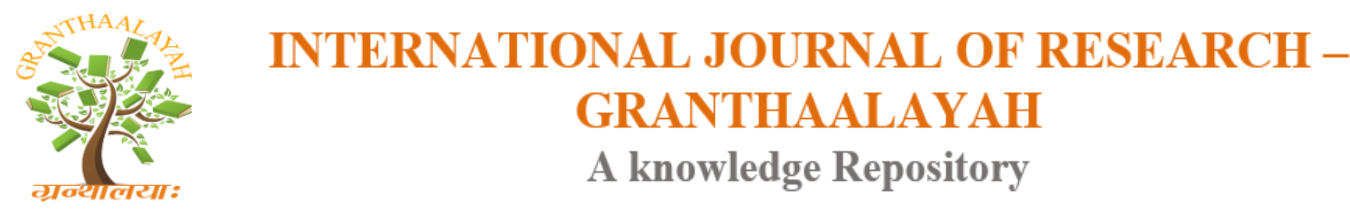

Science

\title{
MEASUREMENTS OF RHEOLOGYCAL AND MECHANICAL-, THERMO-MECHANICAL PROPERTIES OF PVC/CORN COB FOAM COMPOSITE
}

\author{
Krisztina Roman ${ }^{* 1}$, Gabriella Zsoldos ${ }^{2}$ \\ ${ }^{* 1,2}$ Institute of Ceramics and Polymer Engineering
}

\begin{abstract}
In this paper, the modification of PVC/Corn cob blends was investigated. Rheological and diffusion properties of blends are important to learn the behavior of blend's in molten state, because it will provide information necessary for the processing. Nowadays, the development of biomaterials has become a primary goal for material engineers. Using materials from natural sources gives an option to modify PVC structures and properties. The following mechanical properties of the prepared composite were determined; tensile-, bending strength and hardness. The PVC/Corn cob blends have increased impact strength and the other mechanical properties can be improved as well. The relationship between the morphology and properties of the foam were also investigated. The result of DSC and dynamic mechanical analysis showed that the blends form a partially compatible system. The rheological analysis showed that the PVC composite with corn cob could be processed and recycled using regular thermoplastic processing systems.
\end{abstract}

Keywords: PVC/Corn Cob Composite; Foam Rheological Properties; DSC Measurement; DMA Analysis, Mechanical Tests.

Cite This Article: Krisztina Roman, and Gabriella Zsoldos. (2017). "MEASUREMENTS OF RHEOLOGYCAL AND MECHANICAL-, THERMO-MECHANICAL PROPERTIES OF PVC/CORN COB FOAM COMPOSITE." International Journal of Research Granthaalayah, 5(10), 313-321. https://doi.org/10.29121/granthaalayah.v5.i10.2017.2307.

\section{Introduction}

In the recent decade, composites containing natural additives present superior mechanical properties over the basic polymer matrix. The natural additives/fillers reinforced composites are biodegradable, more environment friendly, renewable resources, and non-toxic and light weight materials ${ }^{[1]}$. The potential applications of these fillers are growing rapidly in many industrial areas, because they also have low cost, have significantly reduced harmful effects and low energy consumption during preparation. 
Most of fast developing countries have very rich in agricultures. The farmers produce rice, sugarcane, corn, wheat and lot of other crops, which can be used for biopolymers. Based on different researchers who have been observed that the natural fillers or reinforces have very good physical and mechanical properties. The excellent mechanical properties the fillers can be used in various building applications ${ }^{[2]}$.Many researchers are working in this biomaterials field, and to replace metals or polymers to biomaterials, because they want to increase carrying capabilities and reduce the cost aspects ${ }^{[1]}$.

PVC is a somewhat controversial, although extremely versatile material; therefore, it is very advantageous to make it into bio based composites.

PVC foams morphology, density, mechanical properties were determined, and it was compared to $\mathrm{PVC} / \mathrm{Corn}$ cob properties. In this paper, we examine the inert ant mechanical properties of rigid PVC foams. The PVC foams are currently used as insulating materials. The properties of the foams depend on the material's cell morphology (cells size, shape and wall thickness) and of course the density of the materials ${ }^{[3]}$.

The PVC/Corn cob was mixed in melt; these mixtures have only one glass transition temperate and resonance, which will influence the composition of the mixtures. To get better properties by different polymers or bio fillers can be used, thus the physical characteristics of both materials can be utilized $^{[4]}$.

\section{Materials and Melt Rheology}

For preparing the samples common for PVC foam processing foaming agents, fillers and processing additives (stabilizer, processing aids) were used. For the blends the composition was similar to the neat PVC foam but corn cob powder was added as plus additive.

The PVC used had $\mathrm{K}$ values $=58$, the density was $0,7027 \mathrm{~g} / \mathrm{cm}^{3}$ and MFI $48 \mathrm{~g} / 10 \mathrm{~min}$ $\left(190^{\circ} \mathrm{C} / 5 \mathrm{~kg}\right)$

The chemical compositions of corn cob are usually; $42 \%$ cellulose, $46 \%$ hemicellose, $7 \%$ lignin and the remaining $5 \%$ are other organic compounds ${ }^{[5]}$. The corn cob filler was used in powder form. The powdered additive was dried at $80^{\circ} \mathrm{C}$, after made into fine powder, according to ASTM D1238. The corn cob's density was $1,1252 \mathrm{~g} / \mathrm{cm}^{3}$ The PVC/Corn cob ratio was $100 / 25$ weight ratios. The corn cob's mean particle size was $492 \mu \mathrm{m}$. The results showed that the foam with bio additives gives higher density values, but we would assume that it has lower density values because of the organic components.

\subsection{Rheology Formula}

Melt rheology is the science the flow behaviour and the deformation. It describes the correlation between time, deformation and the driving force. The measurement is representative to the materials properties such as a molecular weight and materials additives ${ }^{[6]}$. The blend's morphology mostly depends on the properties of the pure components, their concentrations and the compatibility between the matrix material and the corn cob additive ${ }^{[7]}$. 
The quotient of the measured voltage values and the corrected deformation velocity values indicated the measure of plastic viscosity. The plastic melt behaves as a non-Newtonian fluid, therefore the viscosity values changes with the deformation field. That is why it can be important to apply the Rabinowitch correction, which is giving the real values of the deformation velocity. The velocity of deformation and viscosity values were determined. From these values, viscosity curves were created at different processing temperatures.

Figure 1, 2 and 3 show the viscosity curves influenced at different temperatures.

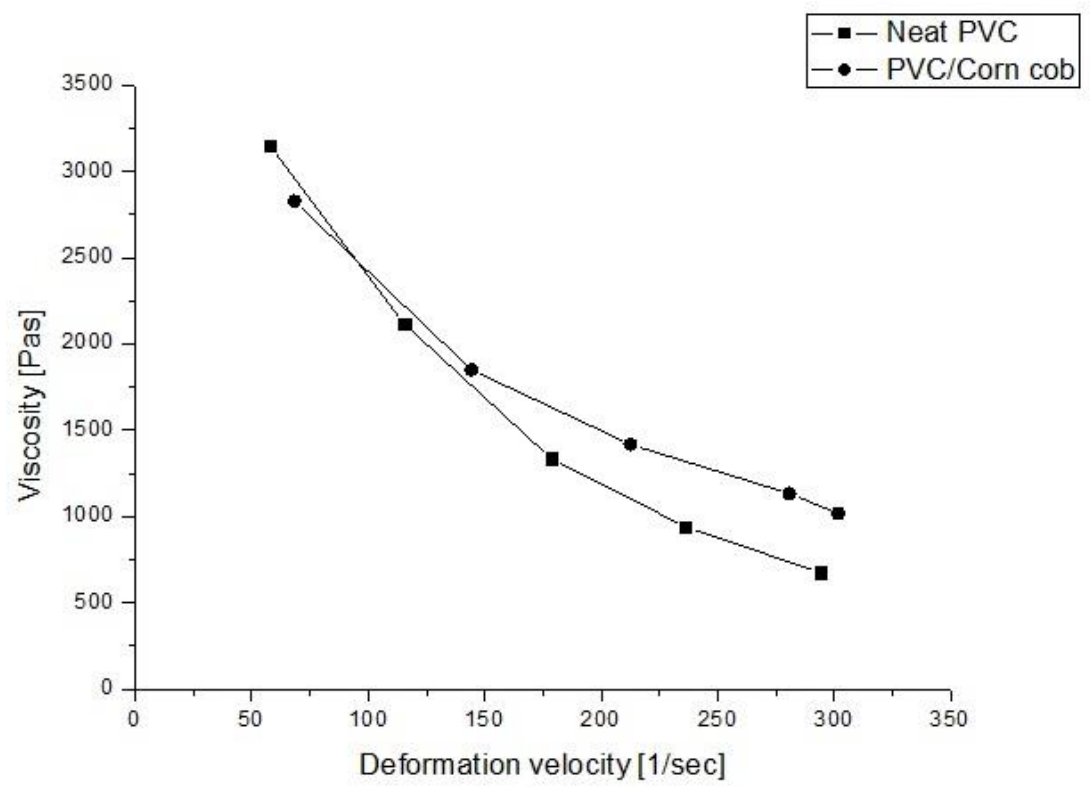

Figure 1: Rheology examination at $180{ }^{\circ} \mathrm{C}$

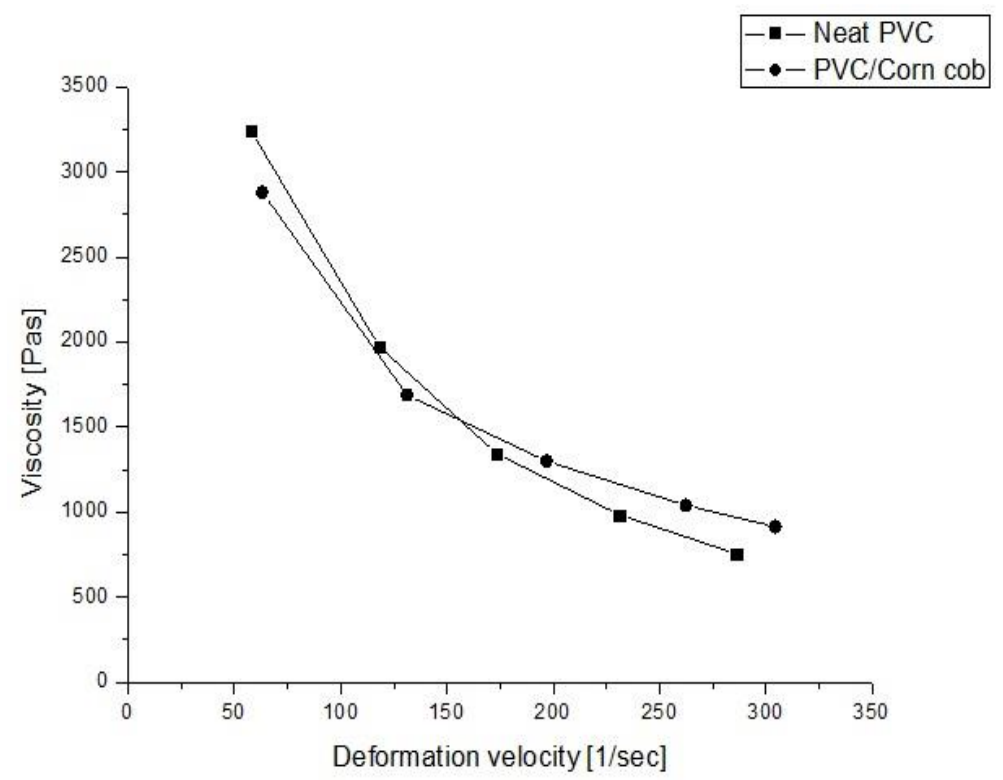

Figure 2: Rheology examination at $190{ }^{\circ} \mathrm{C}$ 


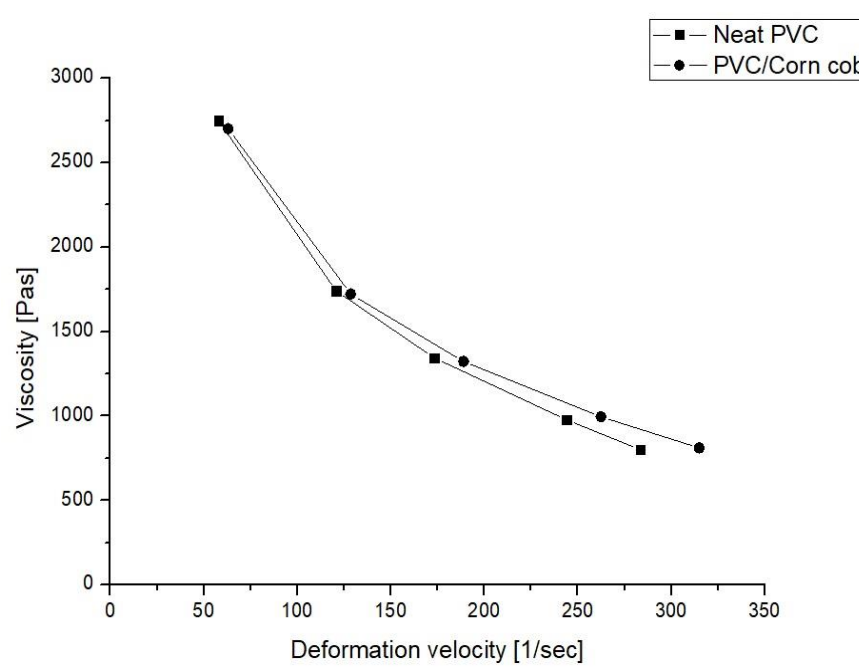

Figure 3: Rheology examination at $200{ }^{\circ} \mathrm{C}$

As you can see from the figures the neat PVC and corn cob foam differ from each other, as the curves are influenced by the cellulose and lignin content of the additive. All PVC/Corn cob foam curves start at higher viscosity and higher deformation velocity at all temperatures. The higher elevated caused the shear stress. Examination of granulated blends is also important because during mixing and compounding, it indicates the deviation of properties of the original (neat PVC)

\subsection{Sample Preparation}

The mixtures were prepared by dry-mixing to $110{ }^{\circ} \mathrm{C}$. All test specimens were prepared on a laboratory extruder at $180^{\circ} \mathrm{C}$ using the same parameters. The samples were cut from the prepared sheets using ZWICK pneumatic punch equipment. Almost all measurements were carried out both in cross and machine directions. We can determine the anisotropy of the material in different orientations. The markings of the Figures title means $\mathrm{M}$ - machine direction, $\mathrm{C}-\mathrm{cross}$ direction of the specimens.

\section{Test Methods and Result Discussions}

\subsection{Hardness Test}

During Shore D tests, the hardness of the materials measured by pressing a steel cone for a few seconds into the surface by a standard load. Usually Shore D measurement used for harder plastics, but in case of our composite, it's harder surface required this method ${ }^{[8]}$. The hardness test properties reported with Zwich/Roell Shore D equipment.

Table 1: Results of hardness test

Samples Mean

Neat PVC foam 39,76

PVC/Corn cob $\quad 66,14$ 


\subsection{Tensile Test}

The tensile and flexural properties measurements were carried out on a INSTON 5566 testing machine according to ASTM D638-10 ${ }^{[9]}$. Test speeds of the tensile tests were $2 \mathrm{~mm} / \mathrm{min}$. The tensile test results contain at Table 2 .

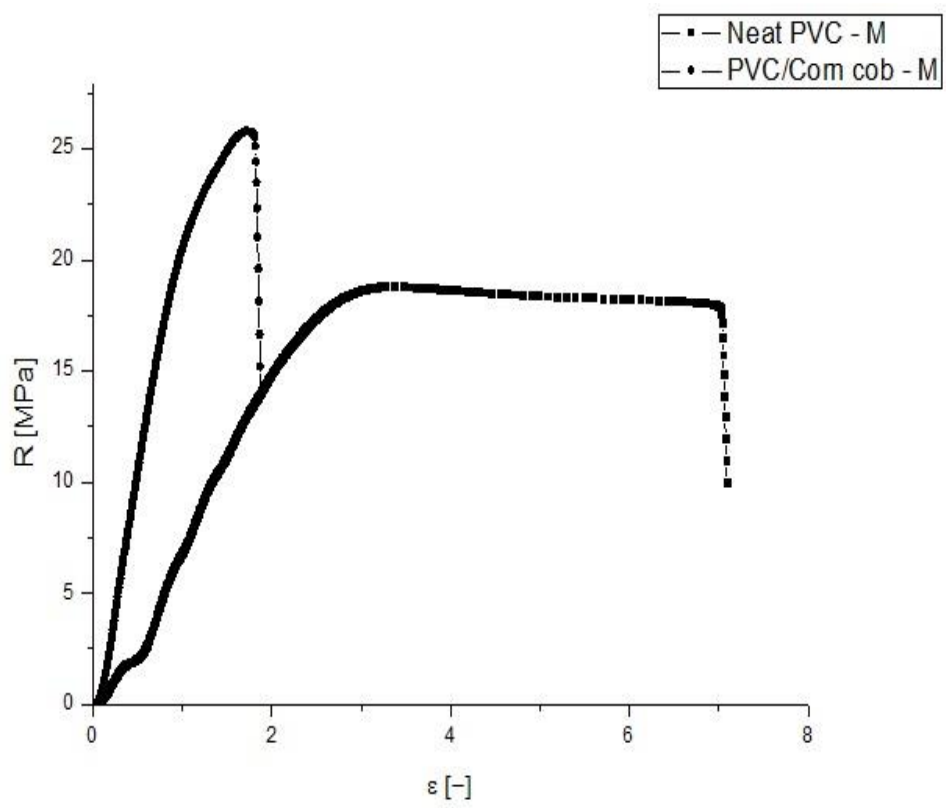

Figure 4: Tensile strength values in machine direction

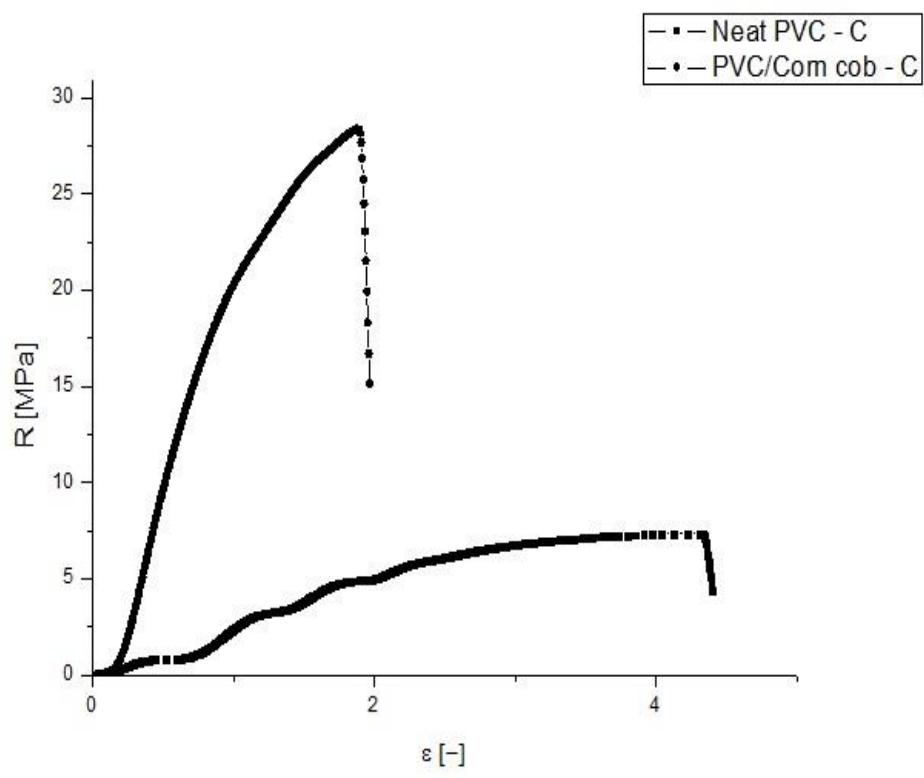

Figure 5: Tensile strength values in cross direction 
Table 2: Results of tensile tests

\begin{tabular}{lc} 
Samples & Max. Tensile \\
Neat PVC - M & 18,83 \\
Neat PVC - C & 7,35 \\
\hline PVC/Corn cob - M & 25,79 \\
PVC/Corn cob - C & 28,37
\end{tabular}

Fisg.4 and 5 show the stress-stain curves of PVC/Corn cob and neat PVC foams in cross- and machine directions. From Fig.4, it is observed that the neat PVC in general displayed significantly longer stain at break than the blends. Otherwise, the blend has much higher strength values, but the ultimate yield was much smaller. In the other direction, the strength-strain curves are similar in shape, but the measured values were lower.

\subsection{Flexural Test}

The tests were carried out at INSTRON 5566 and using 3 points bending head. Table 3. contains the average values of 7 samples (machine and cross direction at each measurement). The standard test method for determining the properties is according to ISO 178:2010 ${ }^{[10]}$. Ten samples were tested and the values average values of flexural strength and modulus were determined.

Table 3: Result of flexural tests

\begin{tabular}{lc} 
Samples & Max. Flexural stress [MPa] \\
\hline Neat PVC - M & 25,19 \\
Neat PVC - C & 7,47 \\
\hline PVC/Corn cob - M & 34,44 \\
PVC/Corn cob - C & 30,53
\end{tabular}

Table 4: Result of flexural tests

Samples Modulus [MPa]

\begin{tabular}{cc} 
Samples & Modulus $[\mathrm{MPa}]$ \\
\hline Neat PVC - M & 902,76 \\
Neat PVC - C & 252,42 \\
\hline PVC/Corn cob - M & 1339,46 \\
PVC/Corn cob - C & 1074,74
\end{tabular}

It can be seen that the corn cob blends have increases flexural stress values. Both the blends and the neat foam show higher stress values in machine direction.

\subsection{DSC Measurement}

DSC (differential scanning calorimetry) is a handy technique for determining changes in physical properties of specimen materials, as function of temperature and time. Calorimetry establishes a connection between temperature and physical properties. Inside the equipments furnace the sample and an empty reference pan is placed. The furnace is heated at linear heating rates; the heat is carried to the sample and the reference pan ${ }^{[11]}$. 
The measurement was carried out on METTLER TOLEDO DSC 823e equipment. The sample weight was $10 \pm 1 \mathrm{mg}$; the applied temperature range was $30-250{ }^{\circ} \mathrm{C}$ with a $20^{\circ} \mathrm{C} /$ minute heating rate.

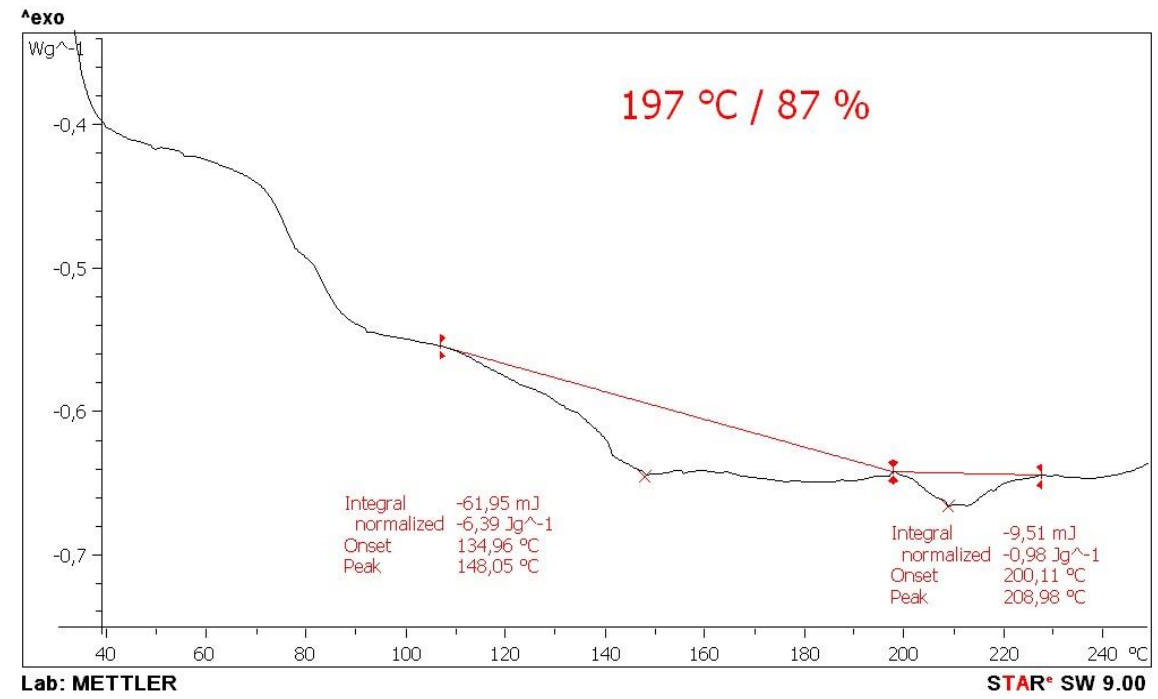

Figure 6: Result of neat PVC DSC analysis

The DSC results show the corn within the blend does not change the thermal properties of the PVC material, because using the same processing temperature, similar digestion percentage of the PVC was observed.

It can be seen that in the die the material was heated up to $196-197^{\circ} \mathrm{C}$ during processing.

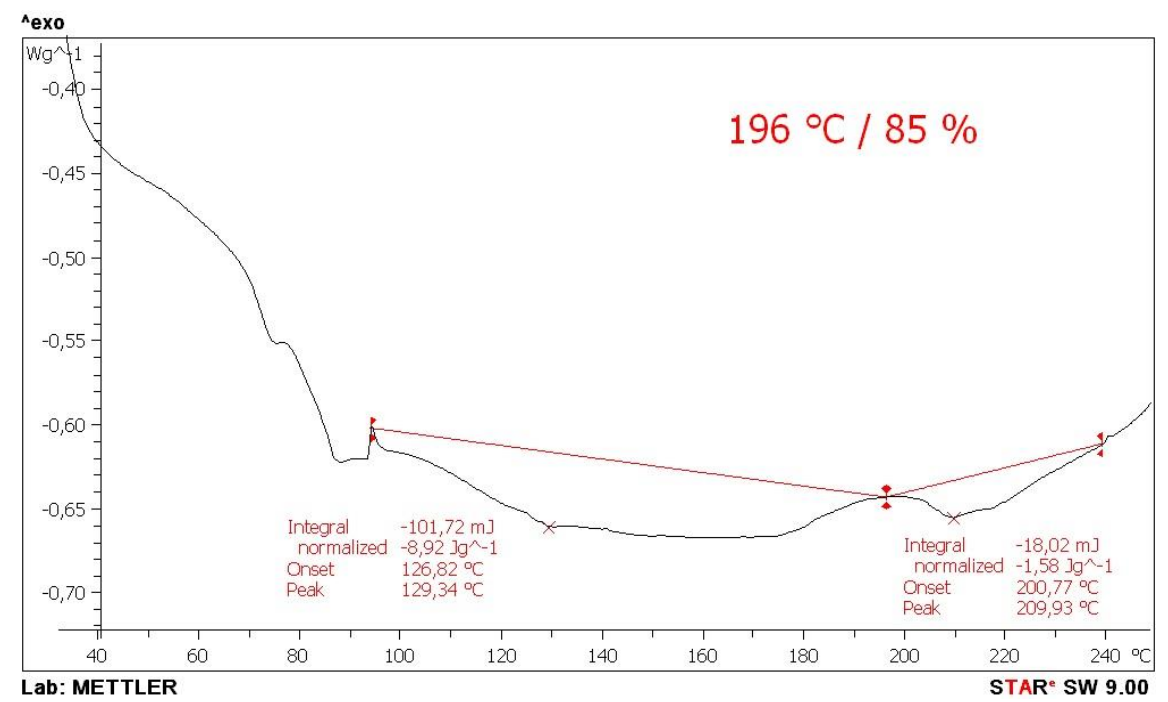

Figure 7: Result of neat PVC by DSC analysis

\subsection{FTIR Analysis}

Fourier transformed infrared spectroscopy was used to measure the chemical components in the polymer products. The FTIR helps to get information about the molecules, additives of material or it can examine the organic pollutants or additives in the mixtures ${ }^{[12]}$. 
The influences of the component of mixtures were investigated by BRUKER TENSOR 27 equipment.

Fig. 8 shows the results of neat PVC- and PVC with corn cob foams. The absorption bands of the base polymer were determined. The absorbance $2920 \mathrm{~cm}^{-1}$ was $\mathrm{C}-\mathrm{H}$ stretch bond of PVC ${ }^{[13]}$. The measurements can be analysed for all components of the two mixtures. The peak at $609 \mathrm{~cm}^{-1}$ and $610 \mathrm{~cm}^{-1}$ are the $\mathrm{C}-\mathrm{Cl}$ stretching vibrations. The peaks at $958 \mathrm{~cm}^{-1}$ and $959 \mathrm{~cm}^{-1}$ show the chain stretch of C-O. From the blend curve between $610 \mathrm{~cm}^{-1}$ and $959 \mathrm{~cm}^{-1}$ the $\mathrm{C}-\mathrm{O}$ chain stretch can be seen in the cellulose. The peaks in the vicinities of $1241 \mathrm{~cm}^{-1}$ and $1243 \mathrm{~cm}^{-1}$ from the original PVC material the $\mathrm{C}-\mathrm{H}$ bend ${ }^{[13]}$. The absorption band at $1328 \mathrm{~cm}^{-1}$ was the degraded cellulose material. In the region of $1424 \mathrm{~cm}^{-1} ; 1426 \mathrm{~cm}^{-1}$ and $2921-2920 \mathrm{~cm}^{-}$the carbonhydrogen vibration of $\mathrm{CH}_{2}$ is observed. Probably the $\mathrm{C}=\mathrm{O}$ carbonyl stretching vibration can be seen at $1732 \mathrm{~cm}^{-1}$.

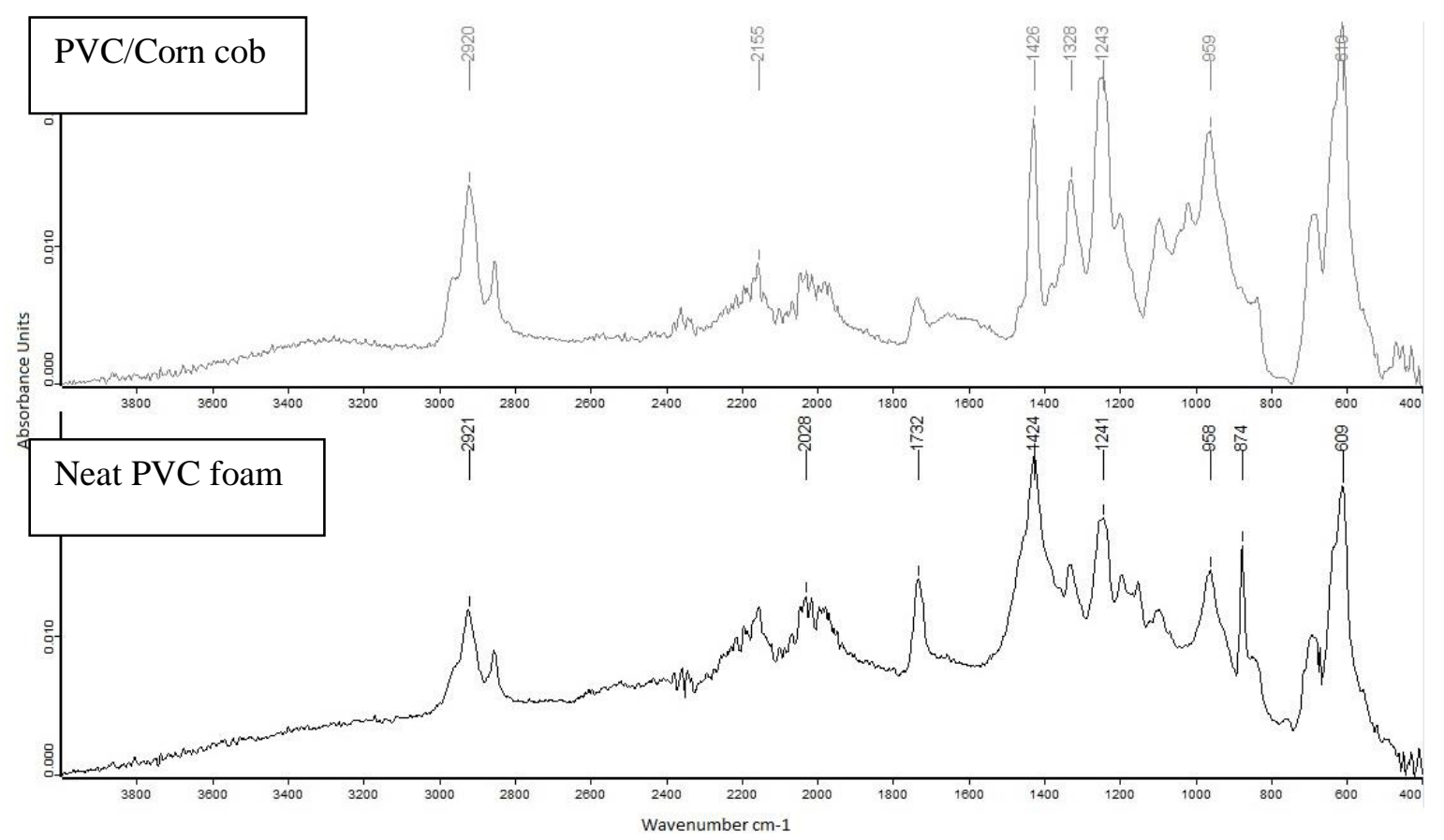

Figure 8: Result of neat and blend

\section{Summary}

The results would seem to suggest that the inner structure of neat and corn cob blend are very similar. The viscosity values of the blend were a little bit higher, but the molecular digestion and the processing temperatures were similar. The values of density prove the blend increasing, furthermore apparent to the hardness results that the corn cob reinforcing the structure of the foam. The mechanical properties are different between the two samples. The tensile stress of the corn cob reinforced PVC blend is about $28 \mathrm{MPa}$, while the neat PVC's maximum tensile stress maximum was about $18 \mathrm{MPa}$. It is visible that the corn cob blend in both directions gave a stronger structure. The bending tests gave similar results than the tensile measurements. The blend is more resistant to the bending owing to the formation of internal reinforcing structures. 


\section{References}

[1] Kiran R. Garadimni, G.U.Raju, K.G. Kodancha, study on Mechanical Properties Of Corn Cob Particle and E-Glass Fiber Reinforces hybrid Polymer Composite, 2015, American Journal of Materials Science, India.

[2] A. Banjo Akinyemi, J.O. Afolayan, E.Ogunji Oluwatobi, Some properties of composite Corn cob and sawdust particle boards, 2016, Construction and Building Materials.

[3] George Wypych, PVC Degradation \& Stabilization, 3nd Edition, Toronto, 2015, 186-198,

[4] Hyun Sik Moon, Won Mook Choi, Mun Ho Kim, O-Ok Park., Miscibility and Rheological Properties of Poly(vinyl chloride)/Stryrene-Acrylonitrile prepared by melt extrusion, 2007, Applied Polimer Science.

[5] Salmah H., M.Z.Marlize and E.Selvi: Biocomposites from Polypropylene and Corn Cob, Effect Maleic Anhydride Polypropylene, 2014, Advances in Civil, and materials research.

[6] Prof. Dr. Alexander Ya.Malkin, Prof. Dr. Avraam I.Isyev, Rheology, Cemtec Publishing, 2006.

[7] L.A.Utracki, Melt rheology of Polymer Blends 1982.

[8] Matweb, Material property data; http://www.matweb.com/reference/shore-hardness.aspx (24.10.2017)

[9] ASTM International;Standard test method for tensile properties of plastic https://www.astm.org/DATABASE.CART/HISTORICAL/D638-10.htm (26.10.2017)

[10] International Organization for standard. https://www.iso.org/standard/45091.html 26.10.2017)

[11] Pooria Gill, Tahereh Tohidi Moghadam, Bijan Ranjbar, Differential Scanning Clorimetry Techniques:applications in Bology and Nanoscience, Journal of Biomolecular techniques, 2010

[12] Intertek; http://www.intertek.com/analysis/ftir/ (25.10.2017)

[13] Robert R. Stromberg, Sidney Straus, Bernard G. Achammer Infrared Spectra of Thermally Degraded Poly (Vinyl Chloride), 1958, Journal of research of the National Bureau of Standard.

*Corresponding author.

E-mail address: polkrisz@ uni-miskolc.hu 